\title{
Incidence and profile of neurological disorders in alcohol dependents
}

\author{
Singh Baghel V. ${ }^{1}$, Shrivastava V. ${ }^{2 *}$ \\ DOI: https://doi.org/10.17511/ijmrr.2020.i03.01 \\ 1 Vijay Singh Baghel, Associate Professor, Department of Medicine, RKDF Medical College Hospital and Research Centre, Bhopal, Madhya \\ Pradesh, India. \\ 2* Vasant Shrivastava, Assistant Professor, Department of Medicine, RKDF Medical College Hospital and Research Centre, Bhopal, Madhya \\ Pradesh, India.
}

Background: Alcohol is one of the most abused substances in the world. Alcohol has been known to produce toxic effects in almost every organ system in the body, many of these medical conditions can be attributed to the direct toxic effect of alcohol and its metabolites, whereas others are indirect sequelae that may result from nutritional deficiency particularly thiamine. A neurological complication of alcohol dependence is extremely common and affects every level of neuroaxis including the Brain-Peripheral nervous system-Muscle. Aim \& Objective: To quantify the number of different neurological disorders in alcohol-dependent patients and to the established relationship between the frequency of these disorders with type, duration, amount, and frequency of alcohol intake. Method \& Material: A cross-sectional study was conducted in 100 alcoholics who came to tertiary care centers of central India in the 1-year duration. Demographic data, questions related to their alcohol consumption, and Neurological examination of all patients were done as pre-decided protocol. Informed consent was obtained from all patients. Data was entered and analyzed using appropriate software. Result: Study participants were mostly (70\%) in the age group of 21 to 40 years, $87 \%$ resided in the urban area, $81 \%$ were Hindu. $78 \%$ were educated up to class $8^{\text {th }}$ and $76 \%$ were employed with any kind of jobs. There were $64 \%$ of cases that had any kind of neurological manifestation, $20 \%$ had peripheral neuropathy and less than $10 \%$ has severe manifestation Korsakoff's psychosis, and cerebellar degeneration. Conclusion: Neurological manifestations were common among alcohol dependents, but it variably depends on the amount, pattern, chronicity, and type of alcohol consumption. There is a need for further studies that specifically point out alcohol-related nervous manifestations.

Keywords: Alcohol, Neurological manifestations, Peripheral Neuropathy, Korsakoff's Psychosis

Corresponding Author

Vasant Shrivastava, Assistant Professor, Department of Medicine, RKDF Medical College Hospital and Research Centre, Bhopal, Madhya Pradesh, India. Email: vasantdr2013@gmail.com
How to Cite this Article

To Browse

Baghel VS, Shrivastava V. Incidence and profile of

neurological disorders in alcohol dependents. Int J

Med Res Rev. 2020;8(3):221-227.

Available From

https://ijmrr.medresearch.in/index.php/ijmrr/article/

view/1185

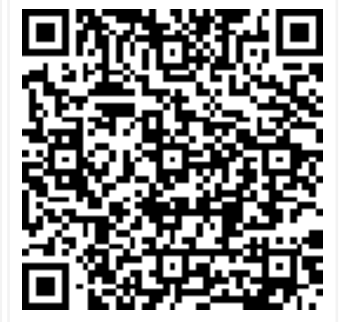

Manuscript Received 2020-04-16

Conflict of Interest No

(c) 2020 by $V i j a$
Review Round 1 2020-04-28

Funding

$\mathrm{Nil}$
Review Round 2 2020-05-06

Ethical Approval Yes
Review Round 3

Plagiarism X-checker $7 \%$
Accepted 2020-05-13

Note 


\section{Introduction}

The term alcohol refers to 'ethyl alcohol'. The quantity differs among the types of alcoholic beverages. The most-commonly used alcoholic beverages are beer, wine, whiskey, rum, vodka, gin, and brandy and locally brewed beverages like arrack and toddy [1]. Alcohol consumption becomes a problem when the individual engages in problematic drinking pattern that puts him at the risk of developing adverse health events. The pattern of drinking started from social drinking to binge drinking that unknowingly leads to harmful to hazardous drinking that ultimately leads to alcohol dependence $[1,2]$. When alcoholic beverages are consumed, alcohol gets absorbed from the stomach and small intestine. It is distributed through blood circulation to every organ in the body. The alcohol gets absorbed by the liver at a rapid pace and excreted through the kidneys, which accounts for $95 \%$ to $98 \%$ of the alcohol consumed [3]. In a study done by Gururaj et al [4], it was concluded that, because of the increase in the alcohol consumption occurring all over the country, the hospital admission rates because of alcohol consumption were also increasing with $20 \%$ to $30 \%$ of admissions because of direct or indirect problems caused because of alcohol consumption. Alcohol consumption not only affects the individuals but also his family members get affected in one way or the other. The person in an intoxicated state may indulge in domestic violence with his family members; may exhaust the savings of the family, which can negatively affect the education of his children, and the children of alcoholic fathers will have strained relationship with their family members, which can affect their psychological wellbeing $[5,6]$. The economic impact of alcohol consumption plays a major role in families belonging to lower socioeconomic strata.7It was found that alcohol-dependent persons spent more money than they earned, they were forced to take loans to spend for their expenses related to alcohol consumption, on an average, 12.2 working days were lost to the habit and around $60 \%$ of the families were financially supported by the income from other family members [8-10]. Although the prohibition of alcohol use is encouraged in the constitution of India, alcohol policy is a state subject. States are having full control of alcoholrelated legislation, excise rates, and the production, distribution, and sale of alcohol [7,11,12]. Alcohol has been known to produce toxic effects in almost
Every organ system in the body, many of these medical conditions can be attributed to the direct toxic effect of alcohol and its metabolites, whereas others are indirect sequelae that may result from nutritional deficiency particularly thiamine [11-12]. Physiological dependence on alcohol is indicated by evidence of tolerance and symptom of withdrawal. Alcohol consumption causes various problems related to different body systems. The main systems which are affected by this are gastrointestinal system, genitourinary system, and muscular system [13-16]. Neurological and psychiatric complication of alcohol dependence is extremely common and affect every level of neuraxis including BrainPeripheral nervous system-Muscle. Intoxication results from the acute pharmacological effect of alcohol and enhancement of neurotransmission in the $\mathrm{Y}$ aminobutyric acid system. The short-term effects of alcohol consumption that can get relieved after stopping alcohol consumption include blackouts, blurred vision, impaired memory, and slower reaction times [17-18]. In a study done by Peng et al [19], it was found that chronic alcohol use can lead to the development of alcoholic tremors, myopathy, Wernicke's encephalopathy, and cerebellar degeneration [19]. With this background, this study aims to quantify different neurological disordered in alcohol-dependent patients and their clinical profile, relationship with type, duration, amount, and frequency of alcohol intake.

\section{Material and method}

Setting: Tertiary care center located in central India.

Type and duration of study- Cross-sectional Study conducted from March 2018 to February 2019.

Sampling Methods: Patients were selected randomly without any bias for age, sex, religion, and type of alcohol consumption.

Sample Size calculation: This study included 100 patients of alcohol dependence. All the patients coming in the center must be included based on inclusion criteria.

Inclusion criteria: All patients who gave informed consent to participate were included in the study.

Exclusion criteria: The alcoholics previously diagnosed and on treatment from the current institute were excluded.

Data collection procedure: Criteria for alcohol dependence are according to DSM- IV. The presence 
Or absence of neurological disorders in a subject was determined by a special questionnaire and physical examination. While registering the patientspecific inquiries were made about occupation, education, monthly income, and family history. Patients were also classified into various socioeconomic statuses based on the BG Prasad method of social classification. It is difficult to measure the alcohol intake in Indians because of the type and the alcohol content present in them.

Study Procedure: Scores were constructed based on attributes of type, quantity, frequency and duration of alcohol intake based on alcohol consumption of subject [20] Inquiries were made from the subjects and their family members about their diet and regarding different type of food consumed. Assessment of the nutritional status of the patient was done by measuring weight and height and body mass index (BMI) was calculated. CAGE scoring was done in every patient as a screening test for alcoholism and a score of more than one was considered diagnostic for alcoholism. After getting a detailed history, patients were examined in detail with special stress on nutrition. Subjective symptoms of peripheral neuropathy like tingling, paresthesias, numbness, and atrophy were noted. the diagnosis of alcoholic peripheral neuropathy was made in the presence of impaired ankle jerk and vibration sense. Patients were also examined for cerebellar signs by Romberg test, difficulty in tandem walking, etc. in absence of peripheral neuropathy patients having positive cerebellar signs were considered to have cerebellar degeneration. Patients were also examined for other system abnormality and routine laboratory investigation were also done

Ethical consideration and Permission: Written informed consent were obtained from all participants and this study was approved by the institutional ethical committee.

Statistical Analysis: All data was entered in Microsoft office excel and presented in the form of frequency and percentage.

\section{Results}

This study was conducted in 100 alcohol-dependent cases to quantify various neurological disorders in them. In this study, all participants were Males. The patients are from different age groups, 70 (70\%) patients were from the age group of 21 to 40 years, $21 \%$ of patients were in the $41-50$ age group, and
Table-1: Demographic data of all patients $(n=100)$.

\begin{tabular}{|c|c|c|}
\hline & Variable & $\begin{array}{l}\text { Frequency } \\
\text { (Percentage) }\end{array}$ \\
\hline \multirow[t]{5}{*}{ Age Group } & $\mid<20$ years & $4(4 \%)$ \\
\hline & $21-30$ years & $31(31 \%)$ \\
\hline & $31-40$ years & 39 (39\%) \\
\hline & $41-50$ years & $21(21 \%)$ \\
\hline & $>50$ years & $5(5 \%)$ \\
\hline \multirow[t]{2}{*}{ Sex } & Male & $100(100 \%)$ \\
\hline & Female & 0 \\
\hline \multirow[t]{2}{*}{ Area } & Rural & $13(13 \%)$ \\
\hline & |Urban & 87 (87\%) \\
\hline \multirow[t]{2}{*}{ Marital Status } & Married & $62(62 \%)$ \\
\hline & Unmarried & 38 (38\%) \\
\hline \multirow[t]{3}{*}{ Religion } & Hindu & $81(81 \%)$ \\
\hline & Muslim & $4(4 \%)$ \\
\hline & Other & $15(15 \%)$ \\
\hline \multirow[t]{5}{*}{ Education Status } & Uneducated & $08(08 \%)$ \\
\hline & Up to Primary Level & $33(33 \%)$ \\
\hline & $\begin{array}{l}\text { Up to Secondary } \\
\text { Level }\end{array}$ & $38(38 \%)$ \\
\hline & $\begin{array}{l}\text { Up to High School } \\
\text { Level }\end{array}$ & $15(15 \%)$ \\
\hline & $\begin{array}{l}\text { Higher secondary\& } \\
\text { Above }\end{array}$ & $06(06 \%)$ \\
\hline \multirow[t]{2}{*}{ Employment Status } & Employed & $76(76 \%)$ \\
\hline & Unemployed & $24(24 \%)$ \\
\hline \multirow[t]{2}{*}{ Type of Liquor consumed } & Country & 68 (68\%) \\
\hline & Foreign & $32(32 \%)$ \\
\hline \multirow{2}{*}{$\begin{array}{l}\text { Hunger in last } 3 \text { month due to } \\
\text { lack of money }\end{array}$} & Yes & $06(06 \%)$ \\
\hline & No & $94(94 \%)$ \\
\hline \multirow[t]{4}{*}{$\begin{array}{l}\text { Frequency of Alcohol } \\
\text { Consumption }\end{array}$} & $\begin{array}{l}\text { Monthly or less than } \\
\text { monthly }\end{array}$ & $20(20 \%)$ \\
\hline & $\begin{array}{l}2 \text { to } 4 \text { times in a } \\
\text { month }\end{array}$ & $37(37 \%)$ \\
\hline & $\begin{array}{l}2 \text { to } 3 \text { times in a } \\
\text { week }\end{array}$ & $16(16 \%)$ \\
\hline & $\begin{array}{l}4 \text { to } 5 \text { times in a } \\
\text { week }\end{array}$ & 27 (27\%) \\
\hline \multirow[t]{5}{*}{ Frequency of Heavy drinking } & Never & $26(26 \%)$ \\
\hline & Less than monthly & $19(19 \%)$ \\
\hline & Monthly & $14(14 \%)$ \\
\hline & Weekly & $20(20 \%)$ \\
\hline & Daily & $21(21 \%)$ \\
\hline
\end{tabular}

Only $5 \%$ of patients in the age group of $>50$ years. $87 \%$ of patients have resided in the urban area and $62(62 \%)$ were married. $81 \%$ patients were Hindu by religion, $4(4 \%)$ were Muslim and $15 \%$ were from other religion especially of Christians community. 8 patients were uneducated, 33\% 
Educated up to primary level, $38 \%$ educated up to secondary level and only $6 \%$ were educated more than higher secondary. $76 \%$ were employed with any kind of job and $24 \%$ were unemployed. $53 \%$ of patients had body mass index (BMI) less than 18.5 , $31 \%$ had normal BMI 18.5 - 24.9, and $16 \%$ had a BMI of more than 25. According to BG Prasad classification, $16 \%$ of patients belong to Class I, $36 \%$ in Class II, $42 \%$ in Class III, $6 \%$ in Class IV socio-economic Status. In this study, $6(6 \%)$ patients suffered from hunger in the last 3 months due to a lack of money. 20 (20\%) Patients had the frequency of alcohol intake monthly and less than monthly while $27 \%$ of patients had 4 to 5 times in a week and $16 \%$ of patients were taking 2 to 3 times a week. When we asked about the frequency of heavy drinking $26(26 \%)$ patients never had an episode of heavy drinking while $19(19 \%)$ had less than monthly, 14 (14\%) monthly, $20(20 \%)$ weekly and $21(21 \%)$ had a daily episode of heavy drinking. $68 \%$ of patients drunk country liquor while $32 \%$ of patients frequently drunk with foreign liquor like Rum or Whiskey. The incidence of neurological disorders showed a positive correlation with the frequency and quantity of alcohol intake and there was a negative correlation between body mass index and frequency of neurological disorders. CAGE scoring was the most efficient screening test for the development of alcohol-related problems. Maximum $46 \%$ patient had CAGE score 3 . In the present study of cases, 64 cases were found to have neurological involvement comprising of peripheral neuropathy 20 $(20 \%)$, hand tremor $16(16 \%)$, hallucinations 14 $(14 \%)$, delirium tremens $14(14 \%)$, withdrawal seizure $10(10 \%)$, blackouts $12(12 \%)$, dementia 4 $(4 \%)$, Korsakoff's psychosis $4(4 \%)$, \& cerebellar degeneration $6(6 \%)$. Most of the patients had more than one manifestation among the withdrawal syndrome, insomnia was the most common (50\% cases). The peripheral neuropathy included mostly tingling and numbness which presents in $80 \%$ cases. The most common sensory disturbance was the loss of vibration sense in $20 \%$ cases. $20 \%$ of cases had objective evidence of peripheral neuropathy with diminished or absent ankle jerk being the most consistent finding, and distal sensory-motor neuropathy was the single most common type, present in $20 \%$ cases. Patients were classified according to their alcohol intake status based on the scoring system of alcohol consumption of subjects [20]. The majority $(74 \%)$ of patients had heavy alcohol consumption (score of 10-12) while $26 \%$ had moderate alcohol consumption (score 4-8), and there was a positive correlation
Between the severity of alcohol intake and frequency neurological disorders. $(r=0.447, p$ $<0.001$ is highly significant) (Table 2 ).

Table-2: Distribution of different neurological problems among patients $(n=100)$.

\begin{tabular}{|l|l|}
\hline \multicolumn{1}{|c|}{ Neurological Problems } & \multicolumn{1}{|c|}{ Frequency (Percentage) } \\
\hline Peripheral Neuropathy & $20(20 \%)$ \\
\hline Hand Tremor & $16(16 \%)$ \\
\hline Hallucinations & $14(14 \%)$ \\
\hline Delirium Tremens & $14(14 \%)$ \\
\hline Withdrawal Seizure & $10(10 \%)$ \\
\hline Blackouts & $12(12 \%)$ \\
\hline Dementia & $04(04 \%)$ \\
\hline Korsakoff's Psychosis & $04(04 \%)$ \\
\hline Cerebellar degeneration & $06(06 \%)$ \\
\hline
\end{tabular}

Mean quantity of alcohol consumption inpatient with the neurological disorder was $413.89 \mathrm{ml}$ ( $\mathrm{t}$-value = 3.782 and $p$-value $<0.0001$ which is highly significant) and showed a positive correlation between the quantity of alcohol consumption \& the presence of neurological disorder and mean frequency of alcohol intake in patients with the neurological disorder was 23.61 days as compared to patients without the neurological disorder (16.56 days) ( $t$ value $=3.244$ and $p$-value $<0.0025$ which is significant).

\section{Discussions}

The present study was conducted in 100 alcoholdependent patients admitted to a tertiary care center of central India. This study had the aim to quantify the occurrence of various neurological symptoms in these alcohols dependent and relate these symptoms with various factors. Alcohol drinking not only affects its health but also causes many social problems. Alcohol drinking increased in a tremendous way in the last two decades. The Problem is also depending on the quantity of drinking, the pattern of consumption (frequency of use, drinking to intoxication, binge drinking, chronic use). The bulk of neuro-positive case in this study comprised of relatively benign and minor illnesses like headache, giddiness mild peripheral neuropathy, cramps, and withdrawal symptoms, etc. severe disabling symptoms and major or specific neurological disease were uncommon. In this study all patients were male, alcohol dependence was not found in any female patients. This shows the greater prevalence of alcohol abuse in males, this is also due to the lower prevalence of alcohol drinking in females and particularly females of the low socio- 
Economic group which constitutes major parts of admission in our hospital, also socio-cultural factors inhibit them from reporting this in the hospital. All most all studies showed similar results [21-27]. This study showed most patients (70\%) belong to the age group of $21-40$ years and only $5 \%$ belong to age more than 55 years. Studies done in various parts of the country showed a similar kind of results $[9,10,17,18]$. The majority of patients $87 \%$ belong to the urban area. This percentage ranges from 20 to $40 \%$ in various studies [28-29]. Some studies showed that chronic health problems are more common in rural areas while alcohol intoxication is more common in the urban population [3]. The overall percentage of alcoholics affected with neurological disorders was $64 \%$. The most common neurological derangement was peripheral neuropathy which was present in $20 \%$ of cases. A similar result was observed in various studies. Peripheral neuropathy was the most common and earliest kind of disorder present in alcoholics. The severity of this disease may depend on the amount, pattern, and chronicity of alcohol drinking [30-35]. Other neurological disorders are also reported in this study. There are fewer studies related to alcohol-related neurological disorders, most of the studies are on the prevalence and pattern of alcohol consumption [36-37]. These alcohol-dependent patients first came in contact with primary level health workers or physicians so initial interventions could take place at this level. There should be the availability of screening of these patients at primary and secondary level health facilities. Also, all health workers should be trained in screening and primary management of these patients. Counseling place an important role in the diagnosis and management of these patients. If necessary, then these patients should be referred to a higher facility for further care and management. This field also needs broad programmatic management and a National health program/policy with specific objectives like alcohol control, production, and promotion policy. In developing countries like India, Multicentric community-based research studies must be conducted at a regular interval to understand the problem in a better way. Our society needed a sensitization program and health education campaign related to the consequences of chronic alcoholism. The major limitation of this study was that it is an institution-based study, not a community-based study and the sample size is small. A larger community-based survey will give a better result about commoner or rarer type neurological disorder.

\section{Conclusion}

The conclusions derived from the observations made are summarized as follows-all patients were male and most of the patients were in the age group of 36-45 years and most of the patients belong to low socioeconomic status, $68 \%$ of patients consumed country liquor and $24 \%$ were consuming whiskey, rum, etc. Peripheral neuropathy is a common neurological manifestation related to alcohol disorders, but another kind of manifestation is also reported. Alcoholics of this study had low literacy levels, low BMI levels, and belong to low socioeconomic status. Several studies in various parts of the country showed similar results. Many times, due to chronic alcoholism, this will lead to a downgrading of their socio-economic status. So Many factors like age, sex, initiation of drinking, Status of living, education, influences, and social life may affect drinking patterns.

\section{What does the study add to the existing knowledge}

This study showed that neurological complications are common among chronic alcoholics and there is better management is possible only when the early diagnosis of these disorders could be done. Early diagnosis is possible only when these diagnosis facilities were provided at the farthest point of the community.

\section{Author's contribution}

Dr. Vijay Singh Baghel: Concept, study design Dr. Vasant Shrivastava: Data analysis, manuscript preparation

\section{Acknowledgment}

Authors are thankful to the faculty of the Department of Medicine, RKDF Medical College Hospital and Research Centre, Jatkhedi, Bhopal, Madhya Pradesh, India without their support and appreciation this work cannot be completed.

\section{Reference}

01. Nayak MB, Bond JC, Cherpitel C. Detecting alcohol-related problems in developing countries- A comparison of 2 screening measures in India. Alcohol Clin Exp Res. 2009;33(12)2057-66.

doi: [Article] [Crossref] 
02. Sachdeva S, Nagar M, Tyagi AK, Sachdeva R. Alcohol consumption practices amongst adult males in a rural area of Haryana. Med J DY Patil. 2014;7(2)128-132.

doi: [Article] [Crossref]

03. Girish N, Kavita R, Gururaj G, Benegal V. Alcohol use and implications for public health Patterns of use in four communities. Indian J Community Med. 2010;35(2)238-244.

doi: [Article] [Crossref]

04. Gururaj G, Isaac MK. In- Psychiatric epidemiology in India- Moving beyond numbers, in Mental Health- An Indian Perspective 19462003, Agarwal SP, Goel DS, Ichhpulani RL, editors. New Delhi- Elsevier. 2005;pp 37-61. [Crossref]

05. Kumar SG, Premarajan KC, Subitha L, Suguna E, Vinayagamoorthy, Kumar V. Prevalence and pattern of alcohol consumption using alcohol use disorders identification test (AUDIT) in rural Tamil Nadu. J Clin Diagn Res. 2013;7(8)16371647.

doi: [Article] [Crossref]

06. Lakshmi A, Daisy D, Duttagupta, Lendi J. Padmanaban Drinking Habits, Health, Social and Behavioural Aspects of Alcohol Users in A Semi Urban Population in Chennai. IOSR-J Dent Med Sciences. 2014;13(12)20-22.

Available at [Article] [Crossref]

07. Dewan G, Chowdhury FR. Alcohol use and alcohol use disorders in Bangladesh. Asia Pac J Med Toxicol. 2015;4;83-90.

doi: [Article] [Crossref]

08. Benegal V, Velayudan A, Jain S. The social costs of alcoholism (Karnataka). NIMHANS $J$. 2000;18;67-76.

[Crossref]

09. Gururaj G, Girish N, Benegal V. Burden and socio-economic impact of Alcohol-The Bangalore Study, Alcohol control series-1. WHO Regional Office for South East Asia. 2006.

Available at [Article] [Crossref]

10. Sathya PM, Attayuru PS, Kandavelu T, Dhanasekara $\mathrm{P}$, Kasturi SP, Vivek B. Alcohol consumption, hazardous drinking, and alcohol dependency among the population of Andaman and Nicobar Islands, India. Ind J Pub Health. 2017;61(2)105-111.

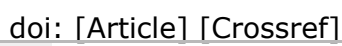

11. Vidhukumar K, Nazeer E, Anil P. Prevalence and pattern of alcohol use in Kerala - A districtbased survey. IJRSTAT. 2016;18(2)363-367. [Crossref]

12. Ramanan VV, Singh SK. A study on alcohol use and its related health and social problems in rural Puducherry, India. J Family Med Prim Care. 2016;5(4)804-808. doi: [Article] [Crossref]

13. Bagnardi V, Blangiardo M, La Vecchia C, Corrao G. Alcohol consumption and the risk of cancerA meta-analysis. Alcohol Res Health. 2001;25(4)263-270.

[Crossref]

14. Kasper DL, Fauci AS, Hauser SL, Longo DL, Jameson JL, Loscalzo J. 2015 Harrison's principles of internal medicine, 19th ed. New York- McGraw Hill Education. 2012; p-2726. [Crossref]

15. Chandra P, Krishna V , Benegal V , Ramakrishna J. High-risk sexual behaviour and sensation seeking among heavy alcohol-users. Indian J Med Res. 2003;117;88-92.

[Crossref]

16. Venkat KK, Arora MM, Singh $P$, Desai $M$, Khatkhatay I. Effect of alcohol consumption on bone mineral density and hormonal parameters in physically active male soldiers. Bone. 2009;45(3)449-454. doi: [Article] [Crossref]

17. Deswal BS, Jindal AK, Gupta KK. Epidemiology of alcohol use among residents of remote hills of Arunachal Pradesh. Indian J Community Med. 2006;31(2)26-30. Available at [Article] [Crossref]

18. Gupta PC, Saxena S, Pednekar MS, Maulik PK. Alcohol consumption among middle aged \& elderly men- A Community Study from Western India. Alcohol Alcoholism. 2003;38(4)327-331. doi: [Article] [Crossref]

19. Peng MC, Chou WJ, Chen SS. Neurological problems in chronic alcoholics. Gaoxiong Yi Xue Ke Xue Za Zhi. 1991;7;404-412. [Crossref]

20. Singh RB, Ghosh S, Niaz MA, Rastogi V, Wander GS. Validation of tobacco and alcohol intake questionnaire in relation to food intakes for the five city study and proposed classification for Indians. J Physicians India. 1998;46(7)587-591. [Crossref] 
21. Dhupdale NY, Motghare DD, Ferreira MA, Prasad YD. Prevalence and pattern of alcohol consumption in Rural Goa. Indian J Community Med. 2006;31(2)104-105. Available at [Article] [Crossref]

22. Reddy MV, Chandrashekar CR. Prevalence of mental and behavioral disorders in India- $A$ meta-analysis. Indian J Psychiatry. 1998;40(2)149-157.

[Crossref]

23. Hazarika NC, Biswas D, Phukan RK, Hazarika D, Mahanta J. Prevalence and pattern of substance abuse at bandardewa, a border area of Assam and Arunachal Pradesh. Indian J Psychiatry. 2000;42(3)262-266.

[Crossref]

24. Jhingan HP, Shyangwa $P$, Sharma A, Prasad KM, Khandelwal SK. Prevalence of alcohol dependence in a town in Nepal assessed by the CAGE questionnaire. Addiction. 2003;98(3)339343.

doi: [Article] [Crossref]

25. Singh J, Singh G, Mohan V, Padda AS. A comparative study of prevalence of regular alcohol users among the male individuals in an urban and rural area of Dist Amritsar Punjab. Indian J Community Med. 2000;25(2)73-78.

Available at [Article] [Crossref]

26. Krishnan A, Shah B, Lal V, Shukla DK, Paul E, Kapoor SK. Prevalence of risk factors for noncommunicable disease in a rural area of Faridabad district of Haryana. Indian J Public Health. 2008;52;117-24. Available at

[Article] [Crossref]

27. Meena, Khanna P, Vohra AK, Rajput R. Prevalence and pattern of alcohol and substance abuse in urban areas of rohtak city. Indian J Psychiatry. 2002;44(4)348-352.

[Crossref]

28. Subramanian SV, Nandy S, Irving M, Gordon D, Davey Smith G. Role of socio-economic markers and state prohibition policy in predicting alcohol consumption among men and women in IndiaA multilevel statistical analysis. Bull World Health Organ. 2005;83(11)829-836.

[Crossref]
29. Mohan D, Chopra A, Sethi H. A rapid assessment study on prevalence of substance abuse disorders in metropolis Delhi. Indian J Med Res. 2001;114;107-114.

[Crossref]

30. Zambelis T, Karandreas N, Tzavellas E, Kokotis $P$, Liappas J. Large and small fiber neuropathy in chronic alcoholdependent subjects. J PeripherNerv Syst. 2005;10(4)375-381. doi: [Article] [Crossref]

31. Vittadini G, Buonocore M, Colli G, Terzi M, Fonte $R$, Biscaldi $G$. Alcoholic polyneuropathy- a clinical and epidemiological study. Alcohol Alcohol. 2001;36(5)393-400. doi: [Article] [Crossref]

32. Ammendola A, Gemini D, Iannaccone $S$, Argenzio F, Ciccone G, Ammendola $\mathrm{E}$, et al. Gender and peripheral neuropathy in chronic alcoholism- a clinical-electroneurographic study. Alcohol Alcohol. 2000;35(4)368-371.

doi: [Article] [Crossref]

33. Ammendola A, Tata MR, Aurilio C, Ciccone G, Gemini D, Ammendola $E$, et al. Peripheral neuropathy in chronic alcoholism- a retrospective cross-sectional study in 76 subjects. Alcohol Alcohol. 2001;36(3)271-275. doi: [Article] [Crossref]

34. Zambelis T, Kanelli S, Tzavellas E, Paparrigopoulos T, Karandreas N. Ulnar Neuropathy at the Elbow in Chronic AlcoholDependent Subjects. J Clin Neuromuscul Dis. 2016;18(1)28-33. doi: [Article] [Crossref]

35. Mygland AMP. Chronic polyneuropathies in VestAgder, Norway. Eur J Neurol. 2001;8(2)157-165. doi: [Article] [Crossref]

36. Masaki T, Mochizuki H, Matsushita S, Yokoyama A, Kamakura K, Higuchi S. Association of aldehyde dehydrogenase-2 polymorphism with alcoholic polyneuropathy in humans. Neurosci Lett. $2004 ; 363(3) 288-290$. doi: [Article] [Crossref]

37. Ghosh S, Samanta A, Mukherjee S. Patterns of alcohol consumption among male adults at aslum in Kolkata, India. J Health Popul Nutr. 2012;30(1)73-81.

doi: [Article] [Crossref] 